\title{
Molecular Detection of Antibiotic Resistance Determinants in Lactobacillus Bacteria Isolated from Human Dental Plaques
}

\author{
Sahar Nouri Gharajalar ${ }^{*}$, Masoumeh Firouzamandi ${ }^{1}$ \\ ${ }^{1}$ Department of Pathobiology, Faculty of Veterinary Medicine, University of Tabriz, Tabriz, Iran
}

Received Oct 24, 2017; Accepted Feb 10, 2018

\begin{abstract}
Introduction: Dental caries is a significant public health problem which destroys the calcified tissues of the teeth. The frequency of lactobacilli in dental caries is usually high. The objective of this study was to evaluate the incidence of these bacteria in dental caries and to identify the antibiotic resistance patterns of them. Methods: Specimens from dental plaque were collected from 30 patients. Phenotypic (Gram staining, cell morphology, and biochemical tests) and molecular (PCR) methods were used for identification of Lactobacillus bacteria. The antimicrobial sensitivity test was performed by standard Kirby-Bauer disk diffusion method to determine their resistance to chloramphenicol, penicillin, vancomycin, nitrofurantoin, cefixime, cefazolin, amoxicillin-clavulanic acid, and tetracycline. Antibiotic resistance genes were detected using multiplex PCR method as well. Results: Fourteen out of $30(46 / 6 \%)$ samples were Lactobacillus positive. The mec $A$ was the essential gene responsible for penicillin resistance. Also, the $b a_{T E M}$ and $b_{0 X X A}$ genes had more significant role in cefazolin and cefixime resistance than $b_{l} a_{S H V}$, and these two genes had the similar role in the amoxicillin-clavulanic acid resistance. Also, tetracycline resistance was caused by both tetK and tet $M$ genes identically. Conclusion: In conclusion, Lactobacillus bacteria had an essential role in the formation of dental plaque and showed multidrug-resistant patterns to commonly used antibiotics. J Med Microbiol Infect Dis, 2017, 5 (3-4): 51-55. DOI: 10.29252/JoMMID.5.3.4.51
\end{abstract}

Keywords: Dental plaque, Lactobacillus, Multiplex PCR, Resistance genes.

\section{INTRODUCTION}

Dental decay is a significant, prevalent chronic problem of the oral cavity [1]. Dental plaques or biofilms, which are formed on teeth surfaces are the primary cause of dental caries and consist of native oral microflora [2]. Lactobacillus species are among the most important organisms contributing the development of dental plaques and dental caries [3]. Cariogenic bacteria like Lactobacillus produce acids as a result of carbohydrate metabolism, which destructs superficial dental structures and leads to dental caries [2]. Selective pressure through administration of antibiotics for the treatment of microbial diseases of the human and animals leads to dissemination and spread of antibiotic resistance genes [4]. Earlier studies showed an overall increase of Lactobacillus species in saliva before the formation of carious lesions. So the Lactobacillus count has been widely used to determine various risk factors including the development of plaque and dental caries [5].

This study was carried out to find the prevalence of Lactobacillus species in dental plaques, and also to determine the antibiotic resistance patterns of the isolates using PCR-based molecular techniques.

\section{MATERIAL AND METHODS}

Study population. Thirty plaque samples were collected from the people attending the dental unit of Tabriz University of Medical Science (TUMS), Tabriz, Iran (2015). Thirty Iranian adult patients (including fifteen men and fifteen women) aged 20-40 years with dental plaque were included in this study. Informed consent was obtained from all participants, and the ethical committee approved the study (No. 2309894.)

Collection of samples. Samples were collected from along the cervical edge of the teeth and then were homogenized by vortexing in a tube containing sterile phosphate- buffered saline (PBS) [6].

Isolation and identification of lactobacilli. Amounts of $0.1 \mathrm{ml}$ of homogenized suspensions were cultured on MRS (Man, Rogosa, and Sharpe) agar (Sigma, USA), and incubated for $48 \mathrm{~h}$ in a $5 \% \mathrm{CO}_{2}$ incubator at $37^{\circ} \mathrm{C}$. The Lactobacillus isolates grown on MRS agar were identified by Gram staining, cell morphology, and biochemical tests, e.g., catalase test, gas production from glucose, arginine hydrolysis, asculin hydrolysis, nitrate reduction and citrate utilization test [7]. The identified Lactobacilli were transferred to MRS broth containing 15\% glycerol and stored at $-20^{\circ} \mathrm{C}[4]$.

Molecular identification of Lactobacilli. An overnight culture of the isolates in MRS broth was used for DNA extraction, and genomic DNA was extracted using a bacterial genomic DNA extraction kit (Fermentase,

${ }^{*}$ Correspondence: Sahar Nouri Gharajalar

Department of Pathobiology, Faculty of Veterinary

Medicine, Tabriz University, Tabriz, Iran, 5166616471

Email: saharnouri@yahoo.com

Tel: +98 (41) 36378743 Fax: +98 (41) 36378734 
Germany). Simply, the cultures were centrifuged for $10 \mathrm{~min}$ at $5000 \mathrm{xg}$, and $10-20 \mathrm{mg}$ of pellets were transferred to 1.5 $\mathrm{ml}$ microtubes and resuspended in $200 \mu \mathrm{l}$ of TE buffer. Amounts of $200 \mu \mathrm{l}$ of the suspensions were mixed with 400 $\mu \mathrm{l}$ of lysis solution and incubated at $65^{\circ} \mathrm{C}$ for $5 \mathrm{~min}$.

Amounts of $600 \mu \mathrm{l}$ of chloroform were added to the mixtures and gently mixed by inverting and then centrifuged at $9400 \mathrm{xg}$ for $2 \mathrm{~min}$. The upper aqueous phase containing DNA was transferred to new tubes, $800 \mu \mathrm{l}$ of freshly prepared precipitation solution was added, mixed gently by several inversions at room temperature for 1-2 min and centrifuged at 9400 for 2 min. The supernatants were removed, and DNA pellets were dissolved in $100 \mu \mathrm{l}$ of $\mathrm{NaCl}$ solution by gentle vortexing. Amounts of $300 \mu \mathrm{l}$ of cold ethanol were added to tubes and kept for $10 \mathrm{~min}$ at $20^{\circ} \mathrm{C}$ and then centrifuged at $9400 \mathrm{xg}$ for $4 \mathrm{~min}$. The ethanol was removed, and DNA pellets were washed with $70 \%$ cold ethanol and dissolved in $100 \mu \mathrm{l}$ of sterile deionized water.

Molecular detection of Lactobacillus bacteria was performed by genus-specific PCR primers F: 5'-CTC AAA ACT AAA CAA AGT TTC-3' and R: 5'- CTT GTA CAC ACC GCC CGT CA-3' , which amplify a ribosomal RNA intragenic spacer region between $16 \mathrm{~S}$ and 23S fragments. The reaction contents for each $25 \mu \mathrm{L}$ PCR consisted of 10 $\mu \mathrm{l}$ Red Amp master mix 2×, $3 \mu$ l of template DNA, $1 \mu \mathrm{l}$ of each primer and $10 \mu$ l of deionized water. The amplification was programmed in a DNA thermocycler (MWG AC BIOTECH THERMAL CYCLER, USA) for 5 min of initial denaturation at $95^{\circ} \mathrm{C}, 20$ cycles of denaturation for $30 \mathrm{~s}$ at $95^{\circ} \mathrm{C}$, annealing for $30 \mathrm{~s}$ at $55^{\circ} \mathrm{C}$ and extension for $30 \mathrm{~s}$ at $72^{\circ} \mathrm{C}$ with a final extension at $72^{\circ} \mathrm{C}$ for $7 \mathrm{~min}$. Amplified products were electrophoresed on $1 \%$ agarose gel at $75 \mathrm{v}$ for $90 \mathrm{~min}$ and visualized under the UV light. A 250 bp band was indicative of the presence of lactobacillus bacteria [4].
Antimicrobial susceptibility pattern. The standard Kirby-Bauer disk diffusion assay was used to identify the antimicrobial agent sensitivity profile of the Lactobacillus isolates with 8 antimicrobial agents, chloramphenicol (30 $\mu \mathrm{g})$, penicillin (10 $\mathrm{U})$, vancomycin $(30 \mu \mathrm{g})$, nitrofurantoin (300 $\mu \mathrm{g})$, cefixime $(5 \mu \mathrm{g})$, cefazolin (30 $\mu \mathrm{g})$, amoxicillinclavulanic acid (20/10 $\mu \mathrm{g})$ and tetracycline (30 $\mu \mathrm{g})$.

A $15 \mathrm{~mm}$ Mueller-Hinton agar plate spread with MRS was inoculated with Lactobacillus and incubated to a turbidity of 0.5 McFarland standards. Seven commercially antimicrobial agent disks were placed on the inoculated plate and were incubated anaerobically at $37^{\circ} \mathrm{C}$ for $18-20 \mathrm{~h}$. The diameters zone of inhibition ( $\mathrm{mm}$ ), around each disk, was measured and interpreted by referring to the performance standard for antimicrobial susceptibility testing [8].

Detection of antibiotic resistance genes by PCR. Based on the resistance phenotypes, three different PCR protocols were used to amplify seven antibiotic resistance genes with the reagents and primers described by others (Table 1). The $b l a_{T E M}$, bla $a_{S H V}$, and $b l a_{O X A-1}$ genes were amplified for the isolates exhibiting cephalosporin (cefazolin and cefixime) resistance[9], blaz and mecA for penicillin resistance[1], and tetK and tet $M$ for tetracycline resistance [10].

\section{RESULTS}

Microscopy and Biochemical tests. Out of 30 samples, 14 lactobacillus isolates (46\%) were obtained. All 14 isolates were Gram-positive rods under oil immersion microscope. They were non-motile and catalase negative, and in the nitrate reduction test, all showed negative reactions.

Table 1. Lactobacillus isolates antimicrobial resistant genes and primer sequences used for PCR identification

\begin{tabular}{|c|c|c|c|c|}
\hline Resistance gene & Primer Sequence & Size (bp) & Annealing temperature $\left({ }^{\circ} \mathrm{C}\right)$ & References \\
\hline bla $_{T E M}$ & $\begin{array}{l}\text { F 5' ATCAGCAATAAACCAGC3' } \\
\text { R 5' CCCCGAAGAACGTTTTC 3' }\end{array}$ & 516 & 54 & {$[9]$} \\
\hline$b^{b l a} a_{S H V}$ & $\begin{array}{l}\text { F 5' AGGATTGACTGCCTTTTTG3' } \\
\text { R 5' ATTTGCTGATTTCGCTCG3' }\end{array}$ & 392 & 54 & [9] \\
\hline bla $_{O X A-1}$ & $\begin{array}{l}\text { F 5'ATATCTCTACTGTTGCATCTCC3' } \\
\text { R 5'AACCCTTCAAACCATCC3' }\end{array}$ & 619 & 54 & [9] \\
\hline blaZ & $\begin{array}{l}\text { F 5' TGA CCA CTT TTA TCA GCA ACC3' } \\
\text { R 5' GCC ATT TCA ACA CCT TCT TTC3' }\end{array}$ & 700 & 58 & [11] \\
\hline $\operatorname{mec} A$ & $\begin{array}{l}\text { F 5'AAA ATC GAT GGT AAA GGT TGG C3' } \\
\text { R 5' AGT TCT GCA GTA CCG GAT TTG C3' }\end{array}$ & 532 & 58 & [11] \\
\hline tetK & $\begin{array}{l}\text { F 5' GTA GCG ACA ATA GGT AAT AGT } 3^{\prime} \\
\text { R 5'GTA GTG ACA ATA AAC CTC CTA3' }\end{array}$ & 360 & 55 & [12] \\
\hline tetM & $\begin{array}{l}\text { F 5' AGT GGA GCG ATT ACA GAA3' } \\
\text { R 5' CAT ATG TCC TGG CGT GTC TA3' }\end{array}$ & 158 & 55 & [12] \\
\hline
\end{tabular}

Table 2. Antimicrobial susceptibility pattern of Lactobacillus isolates obtained from dental plaques

\begin{tabular}{c|cc}
\hline Antimicrobials & Total number of isolates tested & Percentage (\%) of resistant strains \\
\hline Vancomycin & 14 & 64 \\
Chloramphenicol & 14 & 78 \\
Penicillin & 14 & 100 \\
Amoxicillin-Clavulanic acid & 14 & 71 \\
Nitrofurantoin & 14 & 100 \\
$\quad$ Cefixime & 14 & 100 \\
Cefazolin & 14 & 92 \\
\hline Tetracycline & 14 & 2017 Vol. 5 No. 3-4
\end{tabular}


Molecular identification of Lactobacillus genus. All the 14 biochemically identified isolates yielded a 250 bp amplicon indicating the DNA of Lactobacillus genus (Fig. 1) [4].

Antibiotic sensitivity results. Antibiotic susceptibility results of 14 Lactobacillus isolates are shown in Table 2.

The highest resistance rates among the isolates were against penicillin, cefixime, cefazolin, amoxicillinclavulanic acid (100\%) followed by tetracycline (92\%). All the Lactobacillus isolates had resistance to 4 antibiotics, and $57 \%$ showed resistance to all the antibiotics tested. The isolates showed the least resistance rate (64\%) to vancomycin.

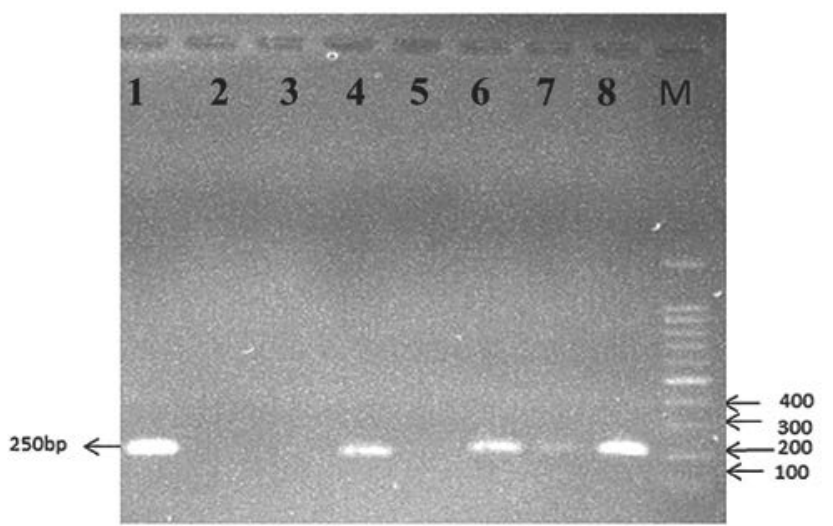

Fig. 1. PCR identification of Lactobacillus genus. M, 100 bp DNA marker; lane 1, positive control (Lactobacillus casei ATCC393); lanes 2 and 3, negative control (Staphylococcus aureus ATCC 12600); lanes 4 to 8, plaque samples

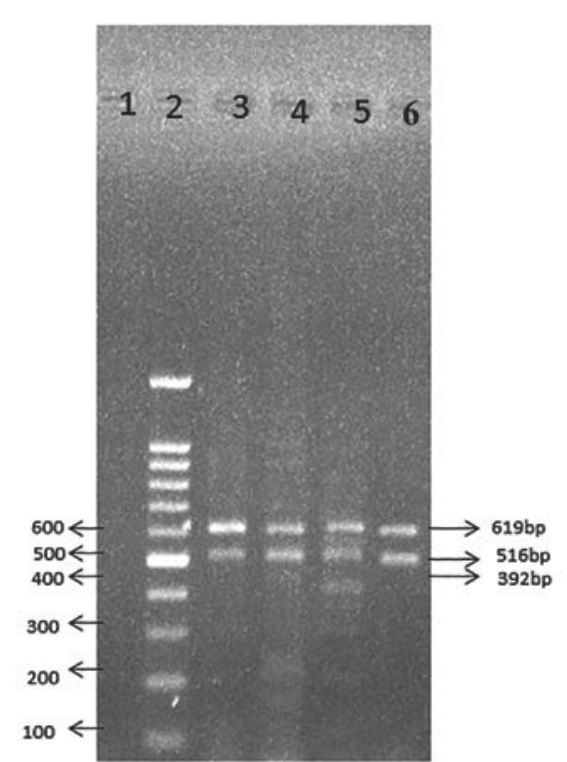

Fig. 3. Agarose gel electrophoresis of products obtained by the second multiplex PCR assay. Lane 1, negative control (Escherichia coli J53); lane 2, 100 bp DNA marker; lane 3, positive control (mixture of E. coli bla $a_{O X A-1}($ ECO71) and E. aerogenes bla $a_{T E M}$ (EAE01) isolates); lanes 4 and 6, bla $a_{T E M}(516$ bp) and bla OXA-1 $_{\text {(619 bp); lane 5, bla }}$ TEM (516 bp), bla $a_{\text {OXA-1 }}$ (619 bp) and $b l a_{S H V}(392 \mathrm{bp})$
Occurrence of antibiotic resistance genes. Among 14 penicillin-resistant isolates, multiplex PCR analysis showed that $14(100 \%)$ had a 532 bp band indicative of mecA gene and $1(2.4 \%)$ had a $700 \mathrm{bp}$ band indicative of blaZ gene (Fig. 2). All the 14 Lactobacillus isolates resistant to amoxicillin-clavulanic acid, cefazolin, and cefixime had 516 bp and 619 bp bands relating to $b a_{T E M}$ and bla $a_{O X A-1}$ genes. One isolate (2.4\%) showed a 392 bp band indicative of bla $_{S H V}$ gene (Fig. 3). Among 13 tetracycline-resistant lactobacilli, all showed 360 bp and 158 bp bands relevant to tetK and tetM genes (Fig. 4). Thus, the results of the multiplex PCR analysis matched with the results of the phenotypic antibiotic resistance patterns.

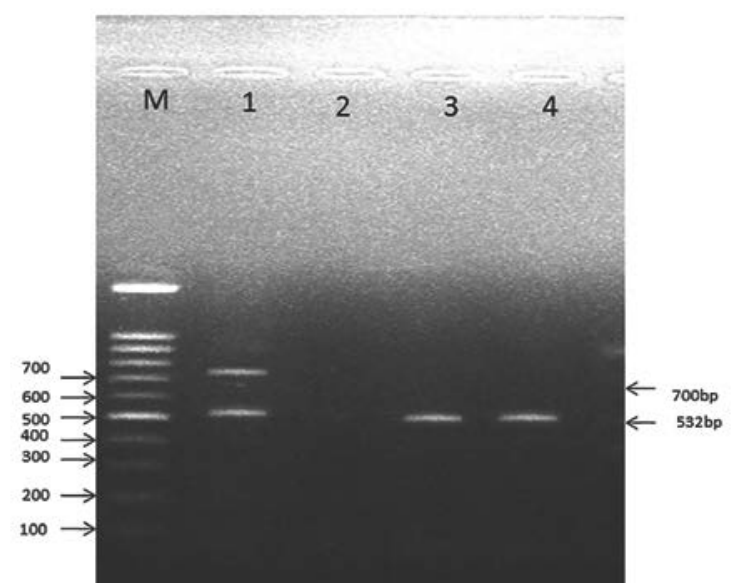

Fig. 2. Agarose gel electrophoresis of products from the first multiplex PCR assay. Lane M, 100 bp DNA marker; lane1, mecA (532 bp) and blaZ (700 bp), lane 3, mecA (532 bp); lane 4, positive control (S. aureus mecA isolate)

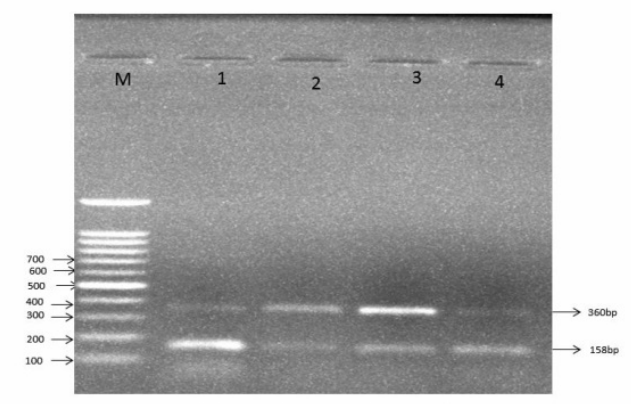

Fig. 4. Agarose gel electrophoresis of products obtained by the third multiplex PCR assay. Lane M, 100 bp DNA marker; lane 1, positive control (S. aureus ATCC 694.01); lanes 2 to 4, tetK (360 bp) and tetM (158 bp) 


\section{DISCUSSION}

The bacteria belonging to Lactobacillus genus have long been known to correlate with dental decay [13]. Dental caries is caused by irreversible solubilization of tooth mineral by acids byproducts of certain bacteria like members of the genus Lactobacillus that adhere to the tooth surface and form dental plaques [10]. In this study, the incidence of Lactobacillus genera in dental plaque samples was studied. We identified Lactobacillus bacteria in $46 \%$ of the dental plaques based on microscopy, biochemical tests, and PCR. In a similar study, Maripandi et al. (2011) didn't report any Lactobacillus from dental caries which contradict with our findings.

Byuan et al. (2004) analyzed the diversity of Lactobacillus species present in progressive dental decays by real-time PCR and found 18 different isolates [14], among which 12 showed a relation with the known Lactobacillus species and only about half of them were similar to the species previously isolated from the human dental caries. The rates they reported are in agreement with our findings, but considerably higher than previous works in which culture-based methods were used [14].

In another study by Daniyan and Abalaka, on frequency and susceptibility profile of bacterial isolates of dental decays, only $6.1 \%$ of the isolates were Lactobacillus, but all the strains were resistant to all the antibiotics used in their trial. In our study, the percentage of Lactobacillus species isolated from dental caries was higher than their results, but all the Lactobacillus isolates showed multidrug-resistant patterns which are similar to their findings [15].

In a study, Matrix-assisted laser desorption/ionization (MALDI) time-of-flight (TOF) mass spectrometry (MS) identified $88.6 \%$ of the lactobacilli isolates, as confirmed by $16 \mathrm{~S}$ rRNA sequencing, in colonies grown from the saliva of the individuals with caries on Rogosa agar media. Their findings confirm the significant role of Lactobacillus in the development of dental caries which is in agreement with our findings [16]. Also, Nouri et al. (2017) studied the prevalence of cariogenic bacteria in dog dental plaques and identified Streptococcus mutans and Streptococcus sobrinus in $8(40 \%)$ and $2(10 \%)$ of samples, respectively. Most of the isolates displayed multidrug resistance patterns to the antibiotics used in the study [17].

The conventional phenotypic analysis for determination of bacterial susceptibility to antimicrobials is now completed by molecular biology assays [4]. In the study of Nouri Gharajalar and colleagues (2017), all the 17 lactobacilli isolated from 30 dental plaque samples showed a multidrug resistance pattern [18]. In this study, we used both phenotypic and genotypic methods for detection of antibiotic resistance genes. All the Lactobacillus isolates had mecA gene, whereas only $2.4 \%$ possessed blaZ gene. These two genes are responsible for penicillin and $\beta$ Lactam antibiotic resistance. So, mecA was the essential gene responsible for penicillin resistance among the lactobacilli isolates. Analyzing of cephalosporin-resistant isolates showed the presence of $b l a_{T E M}$ and $b l a_{O X A-1}$ in all of them, but only $2.4 \%$ had $b l a_{S H V}$ gene. The $\beta$-Lactamases such as the TEM and SHV types belong to the so-called extended-spectrum $\beta$-Lactamases (ESBLs), which can inactivate extended-spectrum Cephalosporins [19]. Here, the $b l a_{T E M}$ and $b l a_{O X A-1}$ genes had higher activity against cefazolin and cefixime. Meanwhile, TEM and OXA-1 enzymes were the most important-Lactamases responsible for amoxicillin-clavulanic acid resistance. According to our results, both genes had the same role in amoxicillinclavulanic acid resistance.

In conclusion, Lactobacilli have an essential role in dental plaques and showed multidrug-resistant patterns which could be screened rapidly using multiplex PCR method.

\section{ACKNOWLEDGEMENT}

This study was supported financially by University of Tabriz, Tabriz, Iran.

\section{ETHICAL APPROVAL}

Here, we declare all ethical standards were respected in preparation of this article.

\section{CONFLICT OF INTEREST}

The authors declare that there are no conflicts of interest associated with this manuscript.

\section{REFERENCES}

1. Kaur N, Sahni P, Singhvi A, Hans MK, Ahluwalia AS. Screening the drug resistance property among aerobic pathogenic microorganisms of dental caries in north-Western Indian population: A preliminary study. J Clin Diagn Res. 2015; 9 (7): ZC06-8.

2. Marip A, Kumar A, Al Salamah AA. Prevalence of dental caries bacterial pathogens and evaluation of inhibitory concentration effect on different tooth pastes against Streptococcus spp. AJMR. 2011; 5 (14): 1778-83.

3. Fayaz M, Sivakumaar PK, Melvin Joe M. Prevalence and antibiotic susceptibility pattern of dental biofilm forming bacteria. Int J Curr Microbiol App Sci. 2014; 3 (5): 46-50.

4. Gad GFM, Abdel Hamid AM, Farag ZSH. Antibiotic resistance in lactic acid bacteria isolated from some pharmaceutical and dairy products. Braz J Microbiol. 2014; 45 (1): 25-33.

5. Roman Mendez C, Badet C, Yanez A, Lilia Dominguez M, Giono S, et al. Identification of oral strains of Lactobacillus species isolated from Mexican and French children. J Dent Oral Hyg.2009;1 (1): 9-16.

6. Franco E, Franco TCC, Amoroso P, Marin JM, Avila FAD. Detection of Streptococcus mutans and Streptococcus sobrinus in dental plaquesamples from Brazilian preschool children by polymerase chain reaction. Braz Dent J. 2007; 18 (4): 329-33.

7. Bhardwaj A, Puniya M, Sangu KPS, Kumar S, Dhewa T. Isolation and biochemical characterization of Lactobacillus species isolated from Dahi. Research \& Reviews: Dairy Sci Technol. 2012; 1 (2): 1-14.

8. Sayah RS, Kaneene JB, Johnson Y, Miller R. Patterns of antimicrobial resistance observed in Escherichia coli isolates 
obtained fromdomestic and wild animal fecalsamples, human septage, and surface water. Appl Environ Microb. 2005; 71 (3): 1394-404.

9. Colom K, Perez J, Alonson R, Fernandez- Aranguiz A, Larino E, Cisterna R. Simple and reliable multiplex PCR assay for detection of blaTEM, bla SHV and bla OXA-1 genes in Enterobacteriaceae. FEMS Microbiol Lett. 2003; 223: 147-51.

10. Loesche WJ. Medical Microbiology. 1996. 4th edition. University of Texas Medical branch at Galveston.

11. Kang MH, Char MJ, Yoon JW, Kim SG, Lee SY, Yoo JH, et al. Antibiotic resistance and molecular characterization of ophthalmic Staphylococcus pseudintermedius isolates from dogs. J Vet Sci. 2014; 15 (3): 409-15.

12. Strommenger B, Kettlitz CH, Werner G, Witte W. Multiplex PCR Assayfor simultaneous detection of nine clinically relevant antibiotic resistance genes in Staphylococcus aureus. J Clin Microbiol. 2003; 41 (9): 4039-94.

13. Caufield PW, Schon CN, Saraithong P, Argimon S. Oral Lactobacilli and dental caries a model for Niche Adaptation in Humans. J Dent Res. 2015; 94 (9): 110-8.
14. Byuan R, Nadkarni MA, Chhour KL, Martin FE, Jacques $\mathrm{NA}$, Hunter $\mathrm{N}$, et al. Quantitative analysis of diverse Lactobacillus species present in advanced dental caries. J Clin Microbiol. 2004; 42 (7): 3128-36.

15. Daniyan SY, Abalaka ME. Prevalence and susceptibility pattern of bacterial isolates of dental caries in a secondary health care institution, Nigeria. Shiraz E Med J. 2011; 12 (3): 135-9.

16. Zhang Y, Liu Y, Ma Q, Song Y, Zhang Q, Wang X, et al. Identification of Lactobacillus from the saliva of adult patients with caries using Matrix Assisted laser desorption/ionization time of flight Mass spectrometry. PLOSONE. 2014; 9 (8): e106185.

17. Nouri Gharajalar S, Hassanzadeh M. Antibacterial properties of Carum copticum essential oil against Streptococcus mutans and Streptococcus sobrinus isolated from canine dental plaque. Vet Med. 2017; 62 (12): 654-60.

18. Nouri Gharajalar S. Molecular characterization of multidrug resistant Lactobacillus isolated from dental plaque of dogs using a multiplex PCR assay. BJVM. 2017; ISSN 1311-1477;

19. Moosdeen F. The evaluation of resistance to Cephalosporins. CID.1997; 24: 487-93. 